Old Dominion University

ODU Digital Commons

Bioelectrics Publications

Frank Reidy Research Center for Bioelectrics

1998

\title{
Generation of Intense Excimer Radiation From High-Pressure Hollow Cathode Discharges
}

Ahmed El-Habachi

Old Dominion University

Karl H. Schoenbach

Old Dominion University

Follow this and additional works at: https://digitalcommons.odu.edu/bioelectrics_pubs

Part of the Electrical and Computer Engineering Commons, and the Inorganic Chemistry Commons

\section{Repository Citation}

El-Habachi, Ahmed and Schoenbach, Karl H., "Generation of Intense Excimer Radiation From High-Pressure Hollow Cathode Discharges" (1998). Bioelectrics Publications. 249.

https://digitalcommons.odu.edu/bioelectrics_pubs/249

\section{Original Publication Citation}

El-Habachi, A., \& Schoenbach, K. H. (1998). Generation of intense excimer radiation from high-pressure hollow cathode discharges. Applied Physics Letters, 73(7), 885-887. doi:10.1063/1.122027

This Article is brought to you for free and open access by the Frank Reidy Research Center for Bioelectrics at ODU Digital Commons. It has been accepted for inclusion in Bioelectrics Publications by an authorized administrator of ODU Digital Commons. For more information, please contact digitalcommons@odu.edu. 


\title{
Generation of intense excimer radiation from high-pressure hollow cathode discharges
}

\author{
Ahmed El-Habachi and Karl H. Schoenbach ${ }^{\mathrm{a})}$ \\ Electrical and Computer Engineering Department, Physical Electronics Research Institute, \\ Old Dominion University, Norfolk, Virginia 23529
}

(Received 2 April 1998; accepted for publication 15 June 1998)

\begin{abstract}
By reducing the diameter of the cathode opening in a hollow cathode discharge geometry to values on the order of $100 \mu \mathrm{m}$, we were able to operate these discharges in noble gases in a direct current mode up to atmospheric pressure. High-pressure discharges in xenon were found to be strong sources of excimer radiation. Highest intensities at a wavelength of $172 \mathrm{~nm}$ were obtained at a pressure of 400 Torr. At this pressure, the vacuum ultraviolet (VUV) radiant power of a single discharge operating at a forward voltage of $220 \mathrm{~V}$ and currents exceeding $2 \mathrm{~mA}$ reaches values between $6 \%$ and $9 \%$ of the input electrical power. The possibility to form arrays of these discharges allows the generation of flat panel VUV lamps with radiant emittances exceeding $50 \mathrm{~W} / \mathrm{cm}^{2}$.

(c) 1998 American Institute of Physics. [S0003-6951(98)02633-3]
\end{abstract}

The increase of pressure in nonequilibrium discharges in noble gases favors excimer formation, a three-body process. The study of nonequilibrium discharge excimer lamps has so far concentrated on barrier discharges. ${ }^{1}$ Barrier discharges are pulsed discharges, operating on such a short time scale that thermalization of the electrons is prevented. Excimer emission efficiencies, defined as the ratio of optical to electric power, of up to $10 \%$ were reported. ${ }^{2}$

A second type of nonequilibrium discharges are hollow cathode discharges. In these discharges the cathode opening has a diameter on the order of twice the width of the cathode fall and the negative glow. This range of operation can be extended to higher pressures by reducing the hole diameter. A reduction of the diameter to $100 \mu \mathrm{m}$ has allowed us to operate direct current hollow cathode discharges in argon and xenon up to atmospheric pressure. ${ }^{3}$ The emission of excimer radiation from microhollow cathode discharges dependent on pressure and discharge current was reported in earlier papers, ${ }^{3,4}$ however, the intensity of the excimer radiation was obtained only in relative units. Absolute measurements of the vacuum ultraviolet (VUV) excimer radiation from high-pressure xenon discharges are described in the following.

The electrodes used in these measurements are molybdenum foils of $100 \mu \mathrm{m}$ thickness, separated by a mica spacer of $200 \mu \mathrm{m}$ thickness, with circular electrode openings of 100 $\mu \mathrm{m}$ diam. Spectral measurements have been performed using a $0.5 \mathrm{~m}$ McPherson scanning monochromator, model 219, with a grating of $600 \mathrm{G} / \mathrm{mm}$ blazed at $150 \mathrm{~nm}$. The discharge chamber with a $\mathrm{MgF}_{2}$ window was mounted directly to the inlet of the monochromator. Before each experiment, the chamber was evacuated to a pressure of $5 \times 10^{-5}$ Torr and then filled with high-purity (99.95\%) xenon. The VUV spectroscopic system is described in Ref. 3.

The xenon spectrum obtained with this discharge is shown in Fig. 1 for various pressures. At 40 Torr, the $147 \mathrm{~nm}$ xenon resonance line dominates the emission spectrum.

${ }^{a)}$ Electronic mail: schoenb@rolls-royce.eng.odu.edu
There are some indications of the first continuum, which extends from the resonance line towards longer wavelength. The second excimer continuum peaking at $172 \mathrm{~nm}$ appears at higher pressures. At pressures greater than 300 Torr, it dominates the emission spectra up to the longest recorded wavelength of $800 \mathrm{~nm}$.

In order to determine the absolute values of the excimer radiation two methods were used. The first one is based on comparing the discharge emission with that of calibrated UV sources, the second one on radiometric techniques. For measurements with calibrated sources, the lamps were mounted directly to the inlet of the monochromator in the same way as the discharge.

The relation between the photomultiplier reading $R(\lambda)$, for emission at a wavelength $\lambda$, within a wavelength interval $d \lambda$, and the radiant power of the discharge $P_{D}(\lambda)$, or the calibrated source $P_{S}(\lambda)$, is as follows:

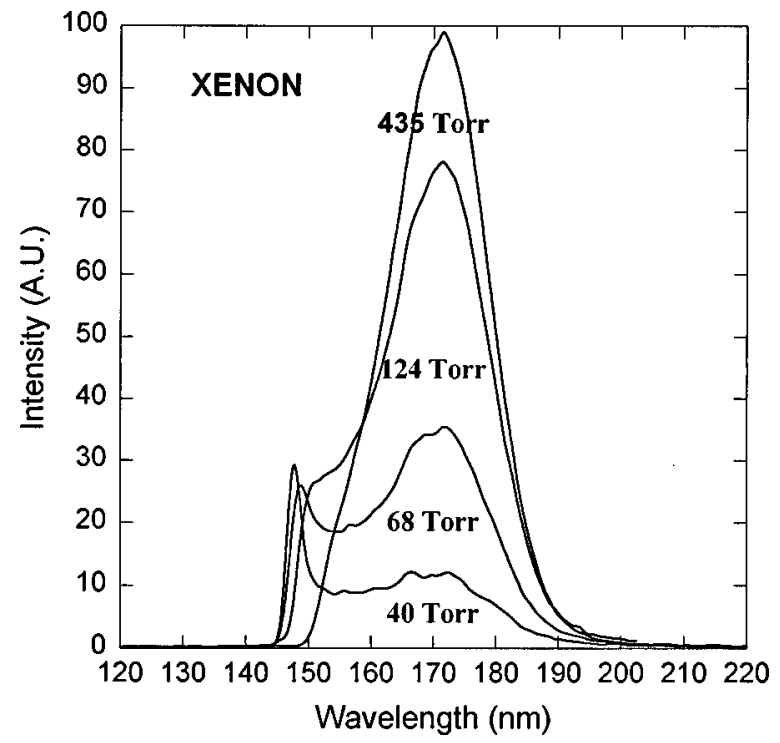

FIG. 1. Pressure dependence of the VUV emission spectrum of highpressure microhollow cathode discharges in xenon. The discharge voltage for any of these measurements was between 215 and $235 \mathrm{~V}$ and the current was kept at 3-3.3 mA. 


$$
\frac{d R_{D, S}(\lambda)}{d \lambda} d \lambda=K(\lambda) P_{D, S}(\lambda) d \lambda
$$

where $K(\lambda)$ is a coefficient which represents the transmission of the monochromator, the detector-scintillator sensitivity, and the ratio between the total radiant power and that incident on the monochromator inlet slit.

For our monochromator grating blazed at $150 \mathrm{~nm}$, the transmission of the instrument between 150 and $200 \mathrm{~nm}$ varies within only a few percent. The scintillator response is also almost flat over the spectral range between 150 and 200 $\mathrm{nm}$. It is, therefore, reasonable to assume that $K$ is a constant in the range of xenon excimer emission. ${ }^{5}$ The photomultiplier reading is related to the radiant power of the source at a given wavelength $\lambda_{0}$, in a wavelength interval $\Delta \lambda_{0}$, which is determined by the resolution of the monochromator:

$$
R_{D, S}\left(\lambda_{0}\right)=K P_{D, S}\left(\lambda_{0}\right) \Delta \lambda_{0} .
$$

It is assumed that the calibrated source is a point source, and that the emission is isotropic. Then the radiant power $P_{S}\left(\lambda_{0}\right)$ at a distance $r^{\prime}$ from the source is related to the calibrated irradiance of the source $H\left(\lambda_{0}\right)$ by

$$
P_{S}\left(\lambda_{0}\right)=4 \pi r^{\prime 2} H\left(\lambda_{0}\right) .
$$

From Eqs. (2) and (3), $K$ can be calculated, and consequently, the absolute value of the excimer emission $P_{D}$ at a given wavelength $\lambda_{0}$ can be obtained.

The total radiant power $P_{T}$ of the discharge is obtained by integrating over the excimer line profile (Fig. 1):

$$
P_{T}=\int_{\lambda_{1}}^{\lambda_{2}} P_{D}(\lambda) d \lambda,
$$

where $\lambda_{1}$ and $\lambda_{2}$ are the lower and upper bounds of the excimer emission, respectively. The discharge efficiency is defined as the ratio of the total radiant power to the input electrical power, which is the product of the discharge current and voltage at a given pressure.

As one calibration source, we have used a mercury lamp (UVP Pen Ray), which is calibrated at a wavelength of 253.7 $\mathrm{nm}$. For the absolute measurements of the xenon emission at $172 \mathrm{~nm}$, however, the $184.9 \mathrm{~nm}$ mercury line was used. The intensity value of this line was obtained by comparing the signals at the two wavelengths and taking the spectral transmission of the system into account. The ratio of the intensity of the $253.7 \mathrm{~nm}$ to the $184.9 \mathrm{~nm}$ line was found to be 25 , which is in agreement with values provided by the manufacturer. ${ }^{6}$ The radiant power of the excimer emission was calculated using Eqs. (2) and (4).

The efficiency versus pressure using this diagnostic technique is shown in Fig. 2. It increases with pressure and reaches a maximum of $7.5 \%$ at 400 Torr. A single discharge at a pressure of 435 Torr, with a current of $3.12 \mathrm{~mA}$ and a forward voltage of $218 \mathrm{~V}$, emits $\approx 53 \mathrm{~mW}$ of VUV radiation concentrated in the spectral range from 150 to $190 \mathrm{~nm}$.

Similar experiments were performed with a deuterium lamp (Oriel BJ2775) with a calibrated spectrum from 160 to $400 \mathrm{~nm} .{ }^{7}$ The deuterium emission at $\lambda_{0}=170 \mathrm{~nm}$ was used as the standard to determine the radiant power of the microhollow cathode discharges excimer radiation. The efficiency

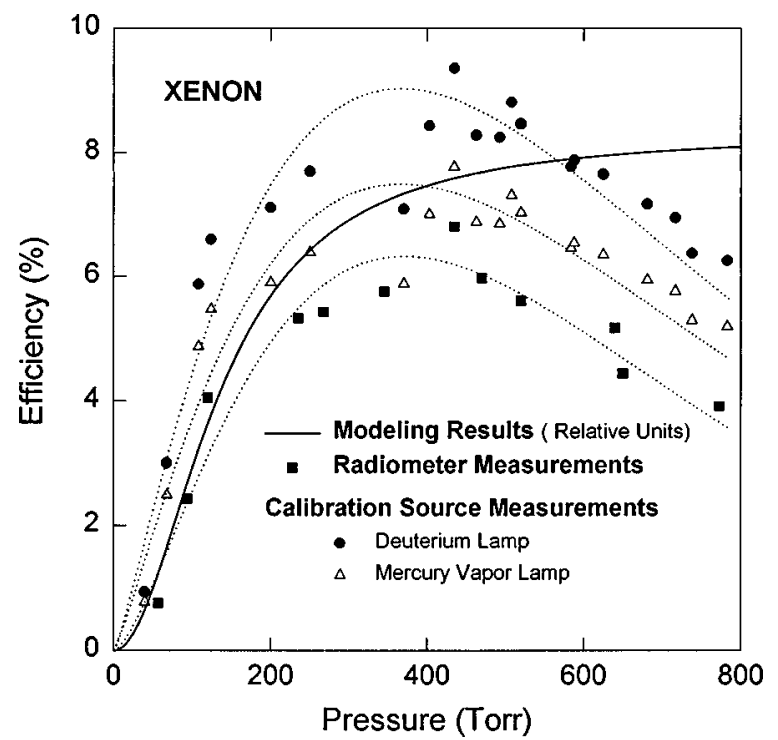

FIG. 2. Measured and calculated efficiency of the xenon excimer radiation vs pressure. The discharge current in these measurements was kept at 3-3.5 $\mathrm{mA}$.

of the discharge obtained with this method is slightly higher than that obtained with the mercury standard (Fig. 2), e.g., $9 \%$ versus $7.5 \%$ at 400 Torr.

In a second method a calibrated radiometer (IL1400) with a calibrated detector (SED185) was used. The detector was mounted on top of the discharge chamber at a distance $r=2.5 \mathrm{~cm}$ from the discharge. An air gap of $6.5 \mathrm{~mm}$ separated the detector from the discharge window. Considering the discharge as a point source, the irradiance reading of the radiometer was converted to a power reading $\mathrm{W}$ by multiplying it by $4 \pi r^{2}$. This power reading is related to the radiant power $P_{D}$ of the discharge:

$$
W=\int_{\lambda_{1}}^{\lambda_{2}} P_{D}(\lambda) T(\lambda) D(\lambda) e^{-\alpha(\lambda) z} d \lambda,
$$

where $T(\lambda)$ is the transmittance of the $\mathrm{MgF}_{2}$ window, which is $\approx 80 \%$ in the range between $\lambda_{1}$ and $\lambda_{2}, D(\lambda)$ is the detector responsivity, $\alpha(\lambda)$ is the absorption coefficient of air, and $z$ is the air gap length. Only the oxygen absorption in the air gap was considered. Absorption of nitrogen is known to be negligible.

In order to solve for $P_{D}(\lambda)$ in the integral equation [Eq. (5)], a fitted function for the relative spectral distribution (Fig. 1), $P_{R}(\lambda)$, was used,

$$
W=P_{0} \int_{\lambda_{1}}^{\lambda_{2}} P_{R}(\lambda) T(\lambda) D(\lambda) e^{-\alpha(\lambda) z} d \lambda,
$$

where $P_{0}$ is a conversion factor from relative power values to absolute ones. Integrating over the excimer line profile [Eq. (4)] provided the value of $P_{0}$, and consequently, the total radiant power.

Again, the efficiency shows a similar pressure dependence as obtained by means of the calibration source method (Fig. 2), however, it is lower by approximately $15 \%$. This is possibly due to water vapor absorption in the air gap, which was neglected in our calculation.

In order to explain the observed pressure dependence of the radiant power of the excimer emission, a simple steady- 
state rate equation model has been used. The two rate equations describing the generation of excited xenon atoms $\mathrm{Xe}^{*}$ and molecules $\mathrm{Xe}_{2} *$ are

$$
\begin{aligned}
& \frac{d\left[\mathrm{Xe}_{2}^{*}\right]}{d t}=\left[\mathrm{Xe}^{*}\right][\mathrm{Xe}]^{2} k_{R}-\frac{\mathrm{Xe}_{2}{ }^{*}}{\tau_{2}}=0, \\
& \frac{d\left[\mathrm{Xe}^{*}\right]}{d t}=\frac{P^{\prime}}{w}-\left[\mathrm{Xe}^{*}\right][\mathrm{Xe}]^{2} k_{R}-\frac{\mathrm{Xe}^{*}}{\tau_{1}}=0,
\end{aligned}
$$

where $P^{\prime}$ is the deposited power in a unit volume of the discharge, $w$ is the mean energy necessary to produce one excited xenon atom, $k_{R}$ is the rate coefficient for the threebody collision $\left[\approx 5 \times 10^{-32} \mathrm{~cm}^{6} / \mathrm{s}\right.$ (Ref. 8 )], $\tau_{1}$ is the apparent lifetime of the excited xenon atoms $[\approx 1 \mu$ s (Ref. 3)], and $\tau_{2}$ is the lifetime of the xenon excimer state $[\approx 0.1 \mu$ s (Ref. 8)]. Diffusion is neglected.

The xenon excimer concentration is derived from Eqs. (7) and (8):

$$
\left[\mathrm{Xe}_{2}{ }^{*}\right]=\frac{P^{\prime}}{w} \frac{k_{R}[\mathrm{Xe}]^{2}}{\left(k_{R}[\mathrm{Xe}]^{2}+\frac{1}{\tau_{1}}\right) \frac{1}{\tau_{2}}} .
$$

If we assume that each excited xenon excimer will decay radiatively, the efficiency can be calculated as

$$
\eta=\frac{\left[\mathrm{Xe}_{2} *\right]^{*} h \nu / \tau_{2}}{P^{\prime}}=\frac{k_{R} p^{2}}{w\left(k_{R} p^{2}+k^{2} T^{2} / \tau_{1}\right)} * h \nu
$$

where $\left[\mathrm{Xe}^{*}\right]$ is expressed in terms of the pressure $p$ using the ideal gas law, and $k T$ is the thermal energy.

The curve obtained this way is shown in Fig. 2. It follows the experimental values up to 400 Torr at $T=300 \mathrm{~K}$. Absolute values, however, differ considerably from experimental ones. If we, e.g., assume a $w$ factor three times the threshold energy for the generation of excited states, the efficiency is calculated as $30 \%-40 \%$, compared to $6 \%-9 \%$ obtained experimentally. This difference in absolute values as well as the deviation between the two curves may be due to diffusion losses, which were neglected in our calculation. Another reason for these discrepancies is photoionization of the $\mathrm{Xe}_{2}{ }^{*}$ excimers, ${ }^{9}$ which is not considered in our model.

The emission of the xenon excimer radiation is, besides on the gas pressure, also dependent on the discharge current. For a discharge at 435 Torr the discharge efficiency and the intensity of the excimer radiation are plotted versus discharge current $I$ in Fig. 3. Typical sustaining voltages are $220 \mathrm{~V}$; these voltage values are lower by a factor of $2 \mathrm{com}-$ pared to previous measurements in xenon. ${ }^{3}$ This reduction in the forward voltage, and an observed increase in excimer radiation at lower pressures, was obtained through careful cleaning and conditioning procedures. The radiation intensity increases linearly with the current and the efficiency strongly increases with current up to $1 \mathrm{~mA}$ and then stays in the range between $5.5 \%$ and $7 \%$ for higher currents.

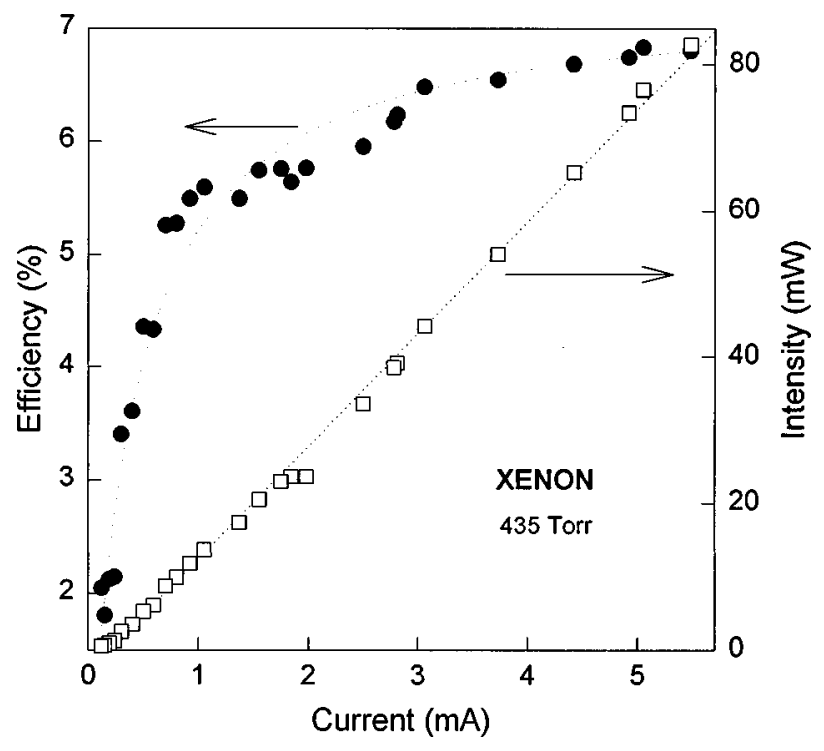

FIG. 3. Intensity of the xenon excimer radiation at $172 \mathrm{~nm}$ vs discharge current and corresponding efficiency. Shown values were measured using the radiometric technique.

The possibility to generate arrays of microhollow cathode discharges ${ }^{10}$ will allow us to fabricate scalable flat panel excimer lamps. Preliminary results of experiments have shown that the hollow cathodes can be spaced at distances equal to the hole diameter. ${ }^{11}$ Under these conditions and assuming that $50 \%$ of the radiant power can be used to irradiate a target, the radiant emittance obtainable based on the single hole result is $65 \mathrm{~W} / \mathrm{cm}^{2}$.

The authors like to thank J. Ametepe and Professor D. Manos (College of William and Mary) for valuable information. This work is supported by the U.S. Department of Energy, Advanced Energy Division.

${ }^{1}$ U. Kogelschatz, B. Elliasson, and W. Egli, Proceedings of the XXIIIrd International Conference on Phenomena in Ionized Gases, Toulouse, 1997, Invited Papers, C4-47.

${ }^{2}$ B. Eliasson and U. Kogelschatz, Appl. Phys. B: Photophys. Laser Chem. 46, 299 (1988).

${ }^{3}$ A. El-Habachi and K. H. Schoenbach, Appl. Phys. Lett. 72, 22 (1998).

${ }^{4}$ K. H. Schoenbach, A. El-Habachi, W. Shi, and M. Ciocca, Plasma Sources Sci. Technol. 6, 468 (1997).

${ }^{5}$ E. Schoeffel, McPherson, Inc., Chelmsford, MA (private communication).

${ }^{6}$ Patrick Lewis, UVP, Inc., Upland, CA (private communication).

${ }^{7} \mathrm{~J}$. Ametepe, College of William and Mary, Williamsburg, VA (private communication).

${ }^{8}$ J. K. Rice and A. W. Johnson, J. Chem. Phys. 63, 5235 (1975).

${ }^{9}$ D. J. Eckstrom, H. H. Nakano, D. C. Lorents, T. Rothem, J. A. Betts, M. E. Lainhart, D. A. Dakin, and J. E. Maenchen, J. Appl. Phys. 64, 1679 (1988).

${ }^{10}$ K. H. Schoenbach, R. Verhappen, T. Tessnow, F. E. Peterkin, and W. W. Byszewski, Appl. Phys. Lett. 68, 13 (1996).

${ }^{11}$ W. Shi and K. H. Schoenbach, Conference Record of the IEEE International Conference on Plasma Science (ICOPS), Raleigh, NC, 1998, 283. 